\title{
Azerbaycan Türkçesinin Bir Diyalektiyle Yazılmış Luka İncili Üzerine
}

\author{
Dr. Öğr. Üyesi Mehdi Rezaei \\ Allameh Tabataba'i Üniversitesi, Fars Edebiyatı ve Yabancı Diller Fakültesi \\ Türk Dili ve Edebiyatı \\ rizai_m613@yahoo.com
}

Öz

İran kütüphaneleri Farsça ve Arapça eserlerin yanı sıra Türkçe kaynaklar açısından da oldukça zengindir. Bu kütüphanelerin arşivlerinde bulunan yüzlerce Türkçe yazma ve basma eser, geçmiş yüzyıllarda Türk dilinin İran coğrafyasında ne kadar etkili olduğunu göstermektedir. İran kütüphanelerinde din, dil, edebiyat, tarih vb. alanlardaki Türkçe eserler son zamanlarda birçok araştırmacının dikkatini çekmiştir. Bu çalışmada, Azerbaycan Türkçesinin bir diyalektine dayanarak tercüme edilmiş Yeni Ahit'in Luka İncili ele alınmıştır. Eserin dil özellikleri üzerinde durulmuş, çevirinin yapıldığı dönemin ağız özellikleri tespit edilmeye çalışılmıştır. Eser Lukanın İncili başlığı altında İran Milli Kütüphanesinde 269 numarayla kayıtlıdır. Eseri incelediğimizde, son yüzyılda İran'da Türkçenin hangi ölçüde değişime uğradığı ortaya çıkmaktadır. Lukanın İncili gösterdiği dil özellikleri itibariyle gerek Azerbaycan Türkçesi gerekse İran Türk ağızları için önemli bir kaynak sayılabilir.

Anahtar Kelimeler: Luka İncili, Azerbaycan Türkçesi, Ağız Özellikleri.

\section{An Investigation of the Gospel of Luke Written in One of the Dialects of Azerbaijani Turkic}

\begin{abstract}
Besides Persian and Arabic works, the libraries of Iran are also enriched by Turkic resources. The presence of hundreds of old printed and handwritten manuscripts in the archives of these libraries recounts the specific status of the Turkish language in Iran's geography in the past centuries. In recent years, with their religious, linguistic, literary, historical, etc. topics, the available works in the libraries of Iran have been considered by many researchers. This paper explores the New Testament Gospel of Luke, which is translated into one of the Azerbaijani dialects. It endeavors to evaluate the linguistic features of the mentioned work and illuminate the properties of the dialect to which the work is translated. This work, namely the Gospel of Luke, has been registered by the 269 number in the national library of Iran. The investigation of the present work will reveal to what extent the Turkish language has undergone changes in the last recent year. Concerning the linguistic features of the Gospel of Luke, the present work can be reckoned as a significant resource for both Azerbaijani Turkic and the other Turkish dialects of Iran.
\end{abstract}

Keywords: Gospel of Luke, Azerbaijani Turkic, Dialectical Properties.

Gönderim Tarihi / Sending Date: 05/06/2020

Kabul Tarihi / Acceptance Date: 19/10/2020 


\section{GİRIŞ}

Türk dili tarihinde dinî metinlerin tercümesi önemli bir yer tutmaktadır. Eski Uygurlar döneminden itibaren çeşitli ayin ve dinlerle ilgili yazılan eserlerin Türkçeye çevrildiği bilinmektedir. Türklerin Müslüman olmasıyla birlikte İslam dinine ait temel kaynaklar Türkçeye çevrilmeye başlamıştır. Bu dinî eserler genellikle bizzat Türkler tarafından tercüme edilmiştir; ancak diğer dinlerle ilgili eserler kimi devirlerde doğrudan o dinlere mensup olan misyonerler tarafından veya onların önayak olmasıyla Türkçeye tercüme edilmiştir. Siyasi ve dinî amaçları bir tarafa bırakırsak bu eserler Türkoloji açısından da oldukça önemlidir. Diğer bir açıdan bakıldığında dinle ilgili metinler, tarih boyunca dillerin korunmasında da etkili bir rol oynamıştır. Ayrıca bu eserler yazıldığı dönemin dil özelliklerini tespit etmemizde de yardımcı olmaktadır.

Kimi kayıtlara göre Hristiyanların kutsal kitabı İncil veya onun bazı bölümleri Eski Uygurlar döneminde Türkçeye çevrilmiştir. Turfan çevresinde İncil'den Uygurcaya çevrilmiş bazı parçalar bulunmuştur (Ercilasun, 2008, s. 260). Oğuz Türkçesi sahasında ise İncil'in ilk tercümesi Ali Ufkî Bey tarafından 1666'da yapılmıştır (Harman, 2002, C. 26, s. 76). Bu dönemden sonra özellikle Osmanlı İmparatorluğu sinırları içinde İncil'in pek çok Türkçe tercümesi yapılmıştır ${ }^{1}$. Son yüzyıllarda, İncil'in Türkçe çevirisi sadece Osmanlı sahasıyla sınırlı kalmayıp Türklerin yoğun olarak yaşadığı diğer ülkelerde de yapılmıştır. $\mathrm{Bu}$ çevirilerden biri de İran'da basıldığı tahmin edilen Lukanın İncili olmuştur.

Bilindiği gibi İran'da Türkçenin varlığı ve bugünkü durumu Türkoloji'de hep ilgi odağı olmuş son zamanlarda birçok araştırmacının dikkatini çekmiştir. Bu ülkede Türkçenin birçok diyalekti konuşulmakta, çeşitli kütüphanelerinde pek çok Türkçe yazma eser bulunmaktadır. Bu makalede Yeni Ahit'in Luka İncili'nin eski bir Türkçe basma nüshası üzerinde durulmuştur. Eserin İslami bir metin değil de Hristiyan inancına ait olması dikkat çekicidir. Söz konusu eserin basılış tarihi net olarak belli olmasa da eserdeki dil verilerine göre XIX. yüzyılda basıldığı tahmin edilmektedir. Bu eseri özel kılan husus onun dilidir. Lukanın İncili, Azerbaycan bölgesinin yaygın bir diyalektine dayanarak tercüme edilmiş, özellikle İran Türklerinin yoğun olarak yaşadığı Azerbaycan ağızlarının özelliklerini büyük ölçüde yansıtmaktadır. Bu gibi eserleri incelediğimizde son zamanlarda İran'da Türkçenin hangi durumda olduğunu ve son yüzyıl içinde nasıl bir değişime² uğradığını tespit etmemiz mümkün olacaktır. Ayrıca eser Oğuz Türkçesi başta olmak üzere Azerbaycan ve İran Türk ağızlarını art zamanlı incelememizde de yardımcı olabilir. Bu hususların yanı sıra bu tarz eserleri dikkate aldığımızda Türkçenin yakın zamana kadar İran'da resmî bir konumda olduğunu ve bir diyalektin nasıl resmî yazı diline dönüştügünü tespit etmek de mümkün olacaktır. Yirmi dört baptan oluşan bu eser, 112 sayfadan ibarettir ve her sayfada 18 satır bulunmaktadir.

\section{Eserin Dil Özellikleri}

Eserin dil özellikleri oldukça dikkat çekicidir. Bilhassa kullanılan dil ile İran Türk ağızları arasında görülen benzerlikler ve farklılıklar ilgi çekicidir. Aşağıda eserin tipik dil özellikleri tespit edilmeye, gerekli durumlarda da ölçünlü Azerbaycan Türkçesi ve İran Türk

\footnotetext{
${ }^{1}$ Geniş bilgi için bk.: Bruce G. Privratsky (2015). Kitabı Mukaddes'in Türkçe Tercümelerinin Tarihçesi, 16 -21 yy. (Çev.: Can Şakırgil). Erişim adresi: https://historyofturkishbible.files.wordpress.com/2015/07/tc3bcrkc3a7e-kmtarihi_version-s.pdf

2 Günümüzde İran Türk ağızları Farsçanın ağır etkisi altında kalarak hızlı bir şekilde yozlaşmaya doğru gitmektedir. Bu etki Türkçenin ses özelliklerinden cümle yapısına kadar görülmektedir.
} 
ağızlarıyla karşılaştırmaya çalışılmıştır. İncelemede daha çok karakteristik hususlar üzerinde durulmuştur.

\section{Ses Bilgisi}

İmla Özellikleri

Eserde düzenli bir imla sisteminin uygulandığını söylemek mümkündür. Eserin geneline baktığımızda aşağıdaki imla özellikleri ön plana çıkmaktadır.

a. Kimi durumlarda sözcüklerin doğru biçimde okunması için harekeler kullanılmıştır. Örneğin oldı "oldu" ve öldi "öldü" fiillerinin birbirinden ayırt edilmesi için (اولدى) ve biçiminde gösterilmiştir. içen (اولدى) ve için (ايحَ) içiniz" gibi sözcükleri birbirinden ayırmak için üstün harekesi kullanılmıştır. İkizleşmeler şedde işaretiyle gösterilmiştir: yéddi "7" (يدّ).

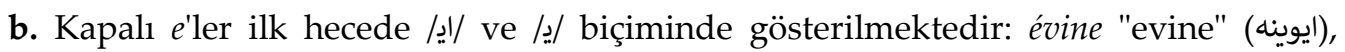
éşitmek "işitmek" (ايشتمك)), géce "gece" (كيجه), vérüb "verip" (ويروب), gétdi "gitti" (كيتدى).

c. Kalın sıradan t'ler bazen /ط/ اطوطوروب), ile yazılmıştır: balta (بالطه), oturub "oturup"

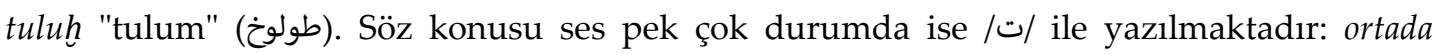

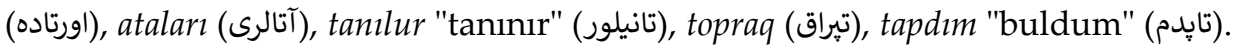

d. Kalın sıradan s'ler genellikle (ص) ile gösterilmiştir: su (صور)), samanı (صون)), savurar "savurur" (صاوورر), saldı (صالدى), soruşacaġam "soracağım" (صوروشهجغ)), sora "sonra" (صورن)).

\section{Ünlü Uyumu}

\section{Kalınlık-incelik uyumu}

Türkçenin temel kurallarından biri olan kalınlık-incelik uyumu, üzerinde çalıştığımız eserde de sağlamdır.

tézlig inen aşağı yén "çabucak aşağı in", ne çetinlik inen dövletli olanlar Allah'ın melekūtına girerler "zenginler zorlukla Allah'ın melekûtuna girerler", onın teri qan damcıları kimi yére tökülür idi "onun teri kan damlaları gibi yere dökülüyordu", sene müjde vérmege gönderilmişem "sana müjde vermek için gönderilmişim", Rebb dédi pes bu neslin adamlarını kime benzedim? "Tanrı 'peki bu neslin insanlarını kime benzeteyim' dedi".

\section{Düzlük-yuvarlaklık uyumu}

Bilindiği gibi Türk dilinin ilk devirlerinde düzlük-yuvarlaklık uyumu sağlam değildi. Eski Oğuz Türkçesinde de bu durum devam etmişti (Timurtaş, 2005, s. 43). Düzlükyuvarlaklık uyumu son zamanlara kadar, bir kısım kökler bir yana, birçok eklere bile hükmünü geçirememiştir (Ergin, 2009, s. 72). Lukanın İncili'nde de bu uyum sağlam değildir. Eski Oğuz Türkçesinin tipik ses özelliklerinden biri olan yuvarlaklaşma söz konusu eserde de birçok durumda görülmektedir. Bu durumları şu şekilde özetleyebiliriz:

Hem öğrenilen geçmiş zaman eki hem de zarf-fiil eki olarak kullanılan -Ub "-Ip/-Up" eki düz ünlülü fiillere de yuvarlak biçimde eklenmektedir.

özini béş ay gizledüb "beş ay saklanmış", 'avratımın güni géçübdür "karımın yaşı ilerlemiştir", her ne ki qaranlıqda danışubsız "karanlıkta konuştuklarını", gelüb uzaqda durdılar "gelip uzakta durdular", o da olara cevāb vérüb dédi "o da onlara cevap verip dedi".

Görülen geçmiş zaman eki genellikle düz ünlü ile gelmektedir. 
gumān éylerdiler ki bir rūḥ gördiler "bir ruh gördüklerini sandılar", qorḩıya düşdi "korkuya kapıldı", İsa'nı görende yüzi üstine düşdi "İsa'yı görünce yüzüstü düştü", onın yanına getürdiler "onun yanına getirdiler", nāžırlıqdan ma'zūl oldım "nazırlıktan atıldım".

Türkçenin her devrinde teklik ve çokluk üçüncü kişi emir ekinin ünlüsü yuvarlak olmuştur. Aynı durumu Lukanın Incili'nde de görebiliriz.

muqāvimet éylemege qādir olmasunlar "mukavemet gösteremeye güçleri yetmesin", şeher içinde olanlar ondan çıhsunlar ve zemilerde olanlar ona girmesünler "şehir içinde olanlar oradan çıksınlar ve tarlalarda olanlar oraya girmesinler".

Şimdiki zaman eki /1/, /n/ ve /ş/ ünsüzleriyle biten fiil kök ve gövdelerine genellikle yuvarlak biçimde eklenir. Bu durum da düzlük-yuvarlaklık uyumunu bozmaktadır.

çöllere aparılur idi "kırlara götürülüyor idi", bir kor adam yol kenarında oturub dilenür idi "bir kör kişi yol kenarında oturup dileniyordu", biz bilürük ki sen doğrı danışursan "biz doğru konuştuğunu biliyoruz", gelmegde yubanur "gelmekte gecikiyor", og̉r yahınlaşur "hırsız yakınlaşıyor", men dalınca gelürem "ben arkandan geliyorum".

Kimi sözcükler eski biçimlerini koruyarak düzlük-yuvarlaklık uyumunun dışında kalmışlardır.

öz sürilerini sahlamaq içün "kendi sürülerini saklamak için", doğrılıq inen "doğru olarak", men bir zemi satun almışam "ben bir tarla satın almışım", sévgülü og̉lımı gönderecegem "sevgili oğlumu göndereceğim", buraya içeri getür "buraya, içeriye getir", üçinci günde qiyam éyliyecekdir "üçüncü gün isyan edecektir", alçaq boylı idi "kısa boyluydu", halq onın sözini éşitmek içün "halk onun sözünü duymak için".

\section{Ses Değişmeleri}

\section{y > v Değişimi}

Eserin en önemli fonetik özelliklerinden biri $\eta>v$ değişimidir. Bu durum teklik ikinci kişi iyelik ekinden sonra yönelme ve belirtme hâli eklerinin gelmesi durumunda ortaya çıar. Aynı durumu İran sahasında da görmemiz mümkündür. Örneğin Erdebil ağızlarının önemli ses özelliklerinden biri $\eta>v$ (Karini, 2009, s. 98) değişimidir.

senin yolıvı "senin yolunu", senin évive "senin evine", şāgirdlerüve yalvardım "öğrencilerine yalvardım", og்lıvı buraya getür "oğlunu buraya getir", senin canıvı senden istiyecekler "senin canını senden isteyecekler", öz dostlarıvı ve qardaşlarıvı ve qovumlarıv ve dövletli qonşılarıvı çağırma "kendi arkadaşlarını, kardeşlerini, akrabalarını ve zengin komşularını çağırma", atava ve anava hürmet éyle "babana ve annene saygı göster", yatag்ıvı götürüb évive gét "yatağını toplayıp evine git", ona dédi senedüvi al ve yaz heştad³ "ona belgeni al ve seksen yaz dedi".

Teklik ikinci kişi iyelik ekinden sonra söz konusu ekler gelmediği takdirde $\eta>v$ değişimi yaşanmaz.

senin og̉lın "senin oğlun", aqam buyurdıġın kimi oldı "beyim buyurduğun gibi oldu", dédi ki qardaşın geldi "kardeşin geldi, dedi".

${ }^{3}$. Günümüzde İran Türk ağızlarının genelinde seksen sayısının yerine Farsça heştad sözcüğü kullanılmaktadır. 


\section{y > y (ø) Değişimi}

İran Türk ağızlarının genelinde görülen bu değişim (Doğan, 2010, s. 81; Karini, 2009, s. 98; Rezaei, 2015, s. 111) çokluk ikinci kişi iyelik ekinde ortaya çıkar. Söz konusu ek, ünlü ile biten sözcüklere -yIz şeklinde eklenirken ünsüz ile biten sözcüklere genellikle -Iz biçiminde eklenmektedir.

sizin atayız bilür "sizin babanız bilir", hezîneyiz her yérde olsa gögliz de orada olacaqdır "hazineniz nerede olursa gönlünüz de orada olacaktır", qabaġıza qoyulan zadlardan yéyin "önünüze konan şeylerden yiyiniz", hātırızda olsun "aklınızda tutun", başızdan bir tük eksik olmıyacaqdır "başınızdan bir saç kılı eksik olmayacaktır", adız göglerde yazılubdur "adınız göklerde yazılmıştır", ama içeriz zulm ve şerāret inen dohıdır "ama içiniz zulüm ve kötülük ile doludur", başızı qavzıyub yuharıya bahıın "başınızı kaldırıp yukarıya bakın".

\section{n > g / q / nq Değişimi}

/y/ sesi /v/ ve /y/ seslerinin yanı sıra /g/, /q/ ve /nq/ gibi seslere de değişmiştir.

gögli sınmışlara şefā bağıışlıyam "gönlü kırılanlara şifa bağışlayayım", şāgirdlere dönüb yalquzca olara dédi "öğrencilerine dönüp yalnızca onlara dedi", bir böyük donqız sürisi dağda otlamaqda var idi "büyük bir domuz sürüsü dağda otlamakta idi".

\section{Ses Korunmaları}

Oğuz Türkçesini dikkate aldığımızda İran ve Azerbaycan sahasında ortaya çıkan bazı ses değişimleri, bu ağızları Anadolu ağızlarından ayıran özellikler olarak karşımıza çıkar. Lukanın İncili eserinin yazıldığı dönemde söz konusu değişimlerin birçoğu henüz gerçekleşmemiştir.

\section{/a/ Sesinin Korunmas1}

İran ve Azerbaycan sahasında /v/ sesinden önce gelen /a/ ünlüsü birçok örnekte yuvarlaklaşmıştır; av ov, avuç ovuc, avun- ovun-, avurt ovurd, kavun qovun, kavurqovur-, kavuş qovuş-, savur- sovur-, tavşan dovşsan vb. örnekler gibi. Ancak eserde av gibi bir örnekte /a/ ünlüsünün korunduğu görülmektedir.

derine apar ve torlarızı av için atın "derine götür ve ağlarınızı av için serin", balıqların avı cehetine "balıkları avlamak için", bundan béle insan avçısı olacaqsan "bundan sonra insan avcısı olacaksin".

Kimi örneklerde yuvarlak ünlü ters bir gelişme göstererek düz ünlüye dönüşmüştür.

eller inen avub yéyer "eller ile ovup yer", be'zilerini öldürecekdirler ve be'zilerini qavacaqdırlar "bazılarını öldürecekler bazılarını ise kovacaklardır", alış vériş éyliyenleri qavmaġa başladı "değiş tokuş yapanları kovmaya başladı", gözlerini de göge qavzamaq istemez idi "göğe kaldırmak istemezdi".

\section{/g/ Sesinin Korunmasi}

Ölçünlü Azerbaycan Türkçesi ve İran Türk ağızlarının genelinde birçok örnekte $g>y$ değişimini yaşanmıştır. Ancak üzerinde çalıştığımız eserin yazıldığı dönemde $g>y$ değişimi henüz gerçekleşmemiştir.

mene kim degdi "bana kim değdi", yüzinin șūreti degişildi "yüzünün biçimi değişildi", dövletli degil "zengin değil", igirmi min nefer inen "yirmi bin kişi ile", bir degirman daşı boynına asılub "bir değirmen taşı boynuna asılmış", bağbanlar onı dögüb yola boş saldılar "bağcılar onu 
dövüp eli boş gönderdiler", vāqi' olan żadlardan heberdār degilsen "gerçekleşen olaylardan haberdar değilsin", iki gögerçin "iki güvercin", egriler düz olacaqlar "eğriler düz olacaktır", kögnegin de almaqdan māni' olma "gömleğini de almasını engelleme", du'a éylemegi bize ögret "dua etmeyi bize öğret".

\section{/q/ Sesinin Korunması}

Günümüzde ölçünlü Azerbaycan Türkçesi ve İran Türk ağızlarında /h/ ile kullanılan kimi sözcükler, eserde q'li şekilde eski biçimlerini korumuştur.

çoq balıq tutdılar "çok balık avladırlar", ondan çoq sözler su'al éyledi "ona birçok soru sordu", altmış oq menzili Urşelim'den uzaq idi "altmış ok menzili Urşelim'den uzaktı", Yahyā'dan böyük péyg்ember yoqdur "Yahya'dan daha büyük peygamber yoktur".

\section{Göçüşme}

Azerbaycan ve İran Türk ağızlarıyla Anadolu ağızları arasında görülen en tipik farklılıklardan biri kimi sözcüklerde yaşanan göçüşme olayıdır. depren- terpen-, ileri ireli, köprü körpü, öksür- öskür-, toprak torpaq, tutsak dustaq, yaprak yarpaq gibi örneklerde söz konusu durumu görebiliriz. Günümüzde Azerbaycan ve İran sahasında göçüşmeye uğramış kimi sözcükler Lukanın İncili'nde orijinal biçimini korumaktadır. Söz konusu sözcükler şunlardır: avrat arvat, tepren- $\sim$ terpen-, topraq $\sim$ torpaq, göster- $\sim$ görset- ${ }^{4}$, yapraq yarpaq.

'avratımın güni géçübdür "karımın yaşı ilerlemiştir", topraq üstünde qayırmış "toprak üzerinde yapmış", siz ki öziyzi adamların ḥuzurunda 'adil gösterirsiz "siz ki kendinizi insanlar huzurunda adil gösteriyorsunuz", aġaclara bahıı yapraqlan açılanda "ağaçlara bakın yaprakları açılınca", onu tepredebilmedi "onu kımıldatamadı".

Eserde kimi örneklerin ikili biçimi kullanılmıştır: örgetmek inen qovmı tehrik éyler "öğretmekle kavmi kışkırtır", doğrı danışursan ve ögredirsen "doğru konuşuyorsun ve öğretiyorsun".

Bazı örneklerde de günümüzde olduğu gibi göçüşme olayı görülmektedir.

ve ireli qaçub onı görmek içün bir tut ag̉acına çıhdı "ve ileri koşup onu görmek için bir dut ağacına çıktı".

\section{Sözcük Başı y- Durumu}

Azerbaycan ve İran Türk ağızlarını Anadolu ağızlarından ayıran diğer bir özellik ise söz başı $y$ - durumudur. yıl il, yılan ilan, yıldırım ildırım, yıldız ulduz (ildız), yiğit $\sim$ igid,

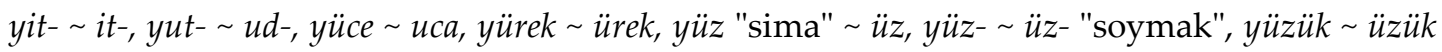
gibi örnekleri dikkate aldığımızda söz konusu durum anlaşılmaktadır. Üzerinde çalıştığımız eserde baktığımızda ise kimi sözcüklerde /y/ ünsüzünün kullanıldığını görmekteyiz. Bu durum günümüzde ölçünlü Azerbaycan Türkçesi ve İran Türk ağızlarında görülmemektedir.

eline yüzük ayaqlarına başmaq vırın "eline yüzük ayaklarına ayakkabı takın", yüzi üste onın ayaqlarına düşüb ona şükr éyledi "yüzüstü onun ayaklarına düşüp ona teşekkür etti", gün inen ayda ve yulduzlarda 'elāmetler olacaq "güneş ile ay ve yıldızlarda alametler olacak",

4. Kimi araştırmacılara göre görset- fiili göster- fiilinin göçüşmeli biçimi değildir. Söz konusu görüşe göre bu fiiller iki farklı yapıya sahiptir. Geniş bilgi için bk.: Ahmet, GÜNŞEN (2006). göster- ve görset- / körset- Fiillerinin Yapısı Üzerine, Sosyal Bilimler Enstitüsü Dergisi, 20, 35-49. 
'avratlar qorhub yüzlerini yére egende "kadınlar korkup yüzlerini aşağı çevirdiklerinde", āyā bizim yüregimiz içimizde alışmaz idi "bizim yüreğimiz içimizde ısınmaz mıdı?", bir yüzüve vurana o birini de ona dönder "yüzünün bir tarafına vuran kişiye diğer tarafı da çevir".

\section{Biçim Bilgisi}

\section{Bildirme Kipleri}

\section{Görülen geçmiş zaman}

Türkçenin bütün devirlerinde gördüğümüz -DI görülen geçmiş zaman eki eserde de aynı biçimde kullanılmaktadır. Bu kipte göze çarpan tek farklılık çokluk ikinci kişi çekiminde ortaya çıkar. Söz konusu durumda $\eta>\emptyset$ değişimi yaşanarak kişi eki $-z$ biçiminde kullanilır.

men yére od salmaġa geldim "ben yere ateş yaymaya geldim", mene bir çepiş vérmedin "bana bir çebiç vermedin", de'vet olunmışlara bir meŝel getürdi "davet edilenlere bir örnek verdi", her zadı terk éyliyüb sene tābi' olduq "her şeyi terk edip sana bağlandık", mérifetin kilidini götürdiz öziz girmediz girenleri de qoymadız "marifetin anahtarını aldınız, kendiniz girmediniz, girenlere de izin vermediniz", şāgirdler bunı görende olara acıqlandılar "öğrenciler bunu görünce onlara kızdılar".

\section{Öğrenilen geçmiş zaman}

Ölçünlü Azerbaycan Türkçesi ve İran Türk ağızlarında olduğu gibi Lukanın İncili'nde de öğrenilen geçmiş zaman için iki farklı ek kullanılmıştır: -Ub ve -mIş. Eseri dikkate aldığımızda $-U b$ eki birinci kişiler için kullanılmazken -mIş eki ise ikinci kişiler için kullanılmamaktadır.

men béş cüft öküz satun almışam "ben beş çift öküz satın almışım", olar ki tedārik éyliyübsen kimin olacaqdır "hazırladıkların kimin olacaktır", her şeherden onın yanına gelüb "her şehirden onun yanına gelmiş", héç bir żad tutmamışıq "hiçbir şey tutmamışız", her ne ki qaranlıqda danışubsız işıqda éşidilecekdir "karanlıkta konuştuklarınızı aydınlıkta duyulacaktır", bizi héyretde qoyublar "bizi hayrette bırakmışlar".

\section{Geniş zaman}

Eserde geniş zaman eki ölçünlü Azerbaycan Türkçesinde olduğu gibi $-r$ ve $-A r$ ekleriyle karşılanır. /l/ ünsüzüyle biten fiil kök ve gövdelerine ek -Ur biçiminde eklenir.

heftede iki def'e oruç tutaram "haftada iki kere oruç tatarım", ondan sora onı kesersen "ondan sonra onu kesersin", ahtaran tapar ve qapı çalana açılur "arayan bulur ve kapı çalana açlır", her ağac öz méyvesinden tanılur "her ağaç kendi meyvesinden tanınır", size beyān éylerem ki o kime benzer "kime benzediğini size açıklarım", biz de her borçlu olanımıza baġışlarıq "biz de bize borçlu olanlara bağışlarız", soframda yéyüb içersiz "soframda yiyip içersiniz", uzun paltarlarda gezmegi isterler "uzun elbiselerle gezmeyi isterler", oruc tutarlar ve dua éylerler "oruç tutarlar ve dua ederler".

\section{Gelecek zaman}

Gelecek zaman eki -acaq / -ecek biçimindedir. Bugün Azerbaycan Türkçesinde birinci kişilerde görülen $k>y$ değişimi eserde görülmemektedir. Ölçünlü Azerbaycan Türkçesinde çokluk ikinci kişi eki -sInIz iken eserde söz konusu ek -sIz biçimindedir.

oları yanına peyġemberler ve resullar gönderecegem "onların yanına peygamberler ve resuller göndereceğim", anbarlarımı yıhıb daha böyüklerini qayıracag்am "ambarlarımı yıkıp 
daha büyüklerini yapacağım", ve sen éy Kefernahum ki göge kimin ucalanubsan cehenneme kimin yéndirileceksen "ve sen ey göğe kadar yükselen Kefernahum cehenneme kadar indirileceksin", oların hansısının 'avratı olacaq "onların hangisinin eşi olacak", vācib olan zadlar size ögredecekdir "vacip olan şeyleri size öğretecektir", çoq fikr éylemeyin ne yiyeceksiz ve bedeniz içün ne giyeceksiz "ne yiyeceğinizi ve ne giyeceğinizi çok düşünmeyin", ona tāziyāne vurub onı öldürecekler "onu kırbaçla vurup öldürecekler".

\section{Şimdiki zaman}

Eserde şimdiki zaman eki -Ir / -Ur şeklindedir. Ünlü ile biten fiillerde ek ünlüsü ile fiilin sonunda bulunan ünlü kaynaşmıştır. Örneğin ölçünlü Azerbaycan Türkçesinde isteyirsen "istiyorsun" biçimindeki çekim eserde istirsen şeklinde kullanılmaktadır. Şimdiki zaman eki /1/,/n/ ve/ş/ ile biten fiil kök ve gövdelerine yuvarlak biçimde eklenmektedir.

her yére gétsen men dalinca gelürem "nereye gitsen ben arkandan geliyorum", ekmedigin zadı biçirsen "ekmediğin şeyi biçiyorsun", oğrn yahınlaşur "hırsız yakınlaşıyor", indi biz Urşelim'e gédirik "şimdi biz Urşelim'e gidiyoruz", biz bilürük ki sen doğrn danışursan "biz senin doğru söylediğini biliyoruz", bu ne sözlerdir ki bir biriz inen beḥ̂s éylirsiz ve ġemgin gédirsiz "niçin bu sözlerden dolayı birbiriyle tartışıp üzgün gidiyorsunuz", girüb orada sākin olurlar "girip orada sakin oluyorlar", özlerini 'adil bilüb güvenürdiler "kendilerini adil bilip güveniyorlardı".

\section{Tasarlama Kipleri}

\section{Gereklilik kipi}

Gereklilik kipi eserde genellikle lāzım ve gerek sözcükleriyle yapılmaktadır. Seyrek de olsa -mAll eki de kullanılmıştır.

tāze şarab tāze tuluhlara qoymalıdır "yeni tulumlara taze şarap koymalıdır", oları terk éylememek lāzım idi "onları terk etmemeliydi", du'a éylemek ve usanmamaq lāzımdır "dua etmek ve usanmamak gerek", senin évinde qalmağım lāzımdır "senin evinde kalmalıyım", menim h̆ușusụumda cemi' yazılmış żadlar gerek tekmil olunsun "benim hakkımda yazılmış tüm şeyler tamamlanmalı".

\section{İstek kipi}

Ölçünlü Azerbaycan Türkçesinde olduğu gibi istek eki eserde de - $(y) A$ biçimindedir.

evvel gédüb atamı defn éyliyem "ilk başta gidip babamı gömeyim", onı atamın évine gönderesen "onu babamın evine gönderesin", o vaqt ki cenūb yéli ese déyersiz ki issi olacaqdır "güney rüzgarı estiğinde sıcak olacak dersiniz", gelin onı öldürek ta irŝ bizimki ola "mirasın bize kalması için onu öldürelim", şūrişler heberlerini éşidesiz qorhmayın "isyanlar haberlerini duyasınız, korkmayın", hükkamin hużurına getüreler "hâkimlerin katına getireler".

\section{Emir kipi}

Eserde görülen emir kipi bugünkü biçimiyle aynıdır; sadece üçüncü kişilerde ek hep yuvarlak şekilde kullanılmıştır.

aqam mene izn vér "efendim bana izin ver", dédi yā rebb gözlerim açılsun "ya rab gözlerim açılsın dedi", siz bu sözleri qulaqlarızda saḩlayın "siz bu sözleri kulaklarınızda tutun", gédüb öziyzi kāhinlere gösterin "gidip kendinizi kâhinlere gösterin", girenler onın işığını görsünler "girenler onun ışığını görsünler". 


\section{Şart Kipi}

Eserde şart kipi günümüzde olduğu gibi -sA ekiyle yapılmaktadır. Birçok örneklerde eger "eğer" sözcügünün de kullanıldığını görmekteyiz.

eger size désem hergiz inanmıyacaqsiz "eğer size desem asla inanmayacaksınız", yā rebb eger istesen meni pāk éylemege qādirsen "ya rab istediğin taktirde beni temizleyebilirsin", her kim özini ucalandırsa alçaqlanur ve her kim ki özini alçaqlandırsa ucalanur "herkes kendisini yüceltirse alçalır ve herkes üstünlük tasarlamasa yücelir", cendek her yerde olsa kerkesler oraya $\mathrm{cem}^{\prime}$ olurlar "ceset her yerde olsa akbabalar oraya toplanurlar", eger dések gögden o da déyecekdir "biz dersek o da gökten seslenecektir", olar sizi qebul éyleseler qabaġiza qoyulan zadlardan yéyin "sizi kabul ederlerse önünüze konan şeylerden yiyiniz".

Kimi durumlarda Farsçanın etkisinde kalarak şart eki kullanılmamaktadır. Bu tarz cümlelerde şart anlamını eger "eğer" sözcüğü sağlamaktadır.

eger Mesih ve Allah'ın bergüzidesidir özini qurtarsun "eğer Mesih ve Allah tarafından seçilmişse kendisini kurtarsın".

\section{Yeterlik Kipi}

Eserde yeterlik kipinin olumlu ve olumsuzu günümüzde olduğu gibi bil- fiiliyle yapılmaktadır.

men 'avrat almışam bu cehete gelebilmerem "ben evlenmişim o yüzden gelemem", bundan sora nāẓir olabilmesen "bundan sonra nazır olamazsın", kim nicāt tapabilür? "kim kurtulabilir?", o çıhanda olar inen danışabilmedi "o çıtığında onlar ile konuşamadı", hem Allah'a hem mala qulluq éyliyebilmezsiz "hem Allah'a hem de mala kulluk edemezsiniz", on söz inen tutabilmediler "onu söz ile önleyemediler".

\section{Zarf-Fiiller}

\section{-Ub zarf-fiil eki}

Türk dilinin tarihî dönemlerinde genellikle yuvarlak biçimde görülen bu ek eserde de hep yuvarlaktır. Söz konusu ek günümüzde İran ve Azerbaycan sahasında genellikle uyuma girmiştir.

olar onı soyub ve yaralıyub nîme can qoyub gétdiler "onlar onu soyup yaralamış, yarı can bırakıp gittiler", gelüb uzaqda durdılar "gelip uzakta durdular", ildırım gög altının bir țerefinden çalub gög altının o țerefine kimin işıqlandııır "yıldırım gök altının bir tarafından çakıp gök altının diğer tarafına kadar aydınlatır", başızı qavzıyub yuharıya bahıın "başınızı kaldırıp yukarıya bakın".

\section{-AndA zarf-fiil eki}

-An sıfat-fiil ekiyle bulunma hâli ekinden oluşan bu ek İran ve Azerbaycan sahasında yaygın bir şekilde kullanılmaktadır. Anadolu sahasında pek görülmeyen bu ek, genellikle IncA/-UncA ekinin karşılığı olarak kullanılır. -AndA zarf-fiil ekinin eski biçimi olan -GAndA Çağatay metinlerinde yaygın olarak görülmektedir.

qayıdanda men sene edā éylerem "dönünce ben sana öderim", qurıya çıhanda şeherden bir adam ona rast geldi "karaya çıkınca şehirden bir insan onunla karşılaştı", onu tapanda çiginlerine qoyar "onu bulunca omuzlarına koyar", olardan biri öz sağalmag்ını görende "onlardan biri kendisinin iyileştiğini görünce", sürende özi yuhladı ve deryāçeye tūfan yéndi "sürerken kendisi uyudu ve denizde fırtına koptu". 


\section{Zamirler}

İran Türk ağızlarının genelinde olduğu gibi eserde de çokluk üçüncü kişi zamiri olar şeklinde kullanılmaktadır. Ayrıca onlar ve bunlar işaret zamirleri de eserde olar ve bular biçiminde karşımıza çıkar.

olar bulardan bir zad anlamadılar "onlar bunlardan bir şey anlamadılar".

\section{Edatlar}

inen "ile"

Eserde gördüğümüz inen edatı ile > ilen > inen gibi bir gelişmenin sonucunda ortaya çıkmıştır. Söz konusu edat eserin yazıldığı dönemde ekleşme eğiliminde de bulunmaktadır. inen edatı veya onun ekleşmiş biçimi olan $-n A n$ bugün İran Türk ağızlarının genelinde de kullanılmaktadır. Muharrem Ergin söz konusu ekleşme sürecini şu şekilde anlatmaktadır: ile edatı - $n$ vasıta ekini alarak ilen şekline geçmiş, eskiden beri kullanılan bu şekil ekleşince -lAn, o da benzeşme ile - $n A n$ şekline girmiştir (Ergin, 2009, s. 370).

göz yaşı inen "göz yaşı ile", bir 'avrat uca ses inen ona dédi "bir kadın yüksek sesle ona dedi", onı söz inen tavlasunlar "onu sözle kandırsınlar", olar inen sofraya egleşende "onlar ile sofraya oturduğunda", bizim inen danışub kitabları bize tefsîr éylerdi "bizimle konuşup kitapları bize yorumlardı", onnan gédir idiler "onunla gidiyorlardı", sennen beraber oturanların "seninle birlikte oturanların", birbiriynen danışur idiler "birbiriyle konuşuyorlardı".

\section{kimin "kadar"}

Ölçünlü Azerbaycan Türkçesinde kimi "kadar" edatı eserde kimin biçiminde kullanılmaktadır. kimin edatı günümüzde İran Türk ağızlarında yaygın olarak kullanılır.

éy imansiz ve ters tāyife ne vaqta kimin sizin inen olam "ey imansız ve uyumsuz kabile ne zamana kadar sizlerle olayım", Hābilin qanından ta Zekeriyya'nın qanına kimin "Habil'in kanından Zekeriya'nın kanına kadar", o vaqtdan indiye kimin "o zamandan şimdiye kadar", men gelene kimin "ben gelene kadar", dağın tepesine kimin apardılar "dağın zirvesine kadar götürdüler".

\section{dekin "kadar"}

Ölçünlü Azerbaycan Türkçesinde görülmeyen bu edat Türkiye Türkçesinde değin şeklinde kullanılmaktadır. İran Türk ağızlarında tekin edatı daha çok "gibi" anlamında kullanılmaktadır (Doğan, 2010, s. 216; Karini, 2009, s. 214; Rezaei, 2015, s. 222).

şeri'et ve péyg்emberler Yehyā'ya dekindir "şeriat ve peygamberler Yahya'ya kadardır", oları éşige Béyt-i 'Enyā'ya dekin apardı "onları dışarı Beyt-i Anya'ya kadar götürdü".

\section{kimi "gibi"}

İan ve Azerbaycan sahasında yaygin olarak kullanılan kimi "gibi" edatı eserde de birçok örnekte görülmektedir.

siz bu adamı halqı azdıran kimi menim yanıma getürdüz "siz bu kişiyi insanları azdıran gibi benim yanıma getirdiniz", sözleri olara efsāne kimi görinüb inanmadılar "sözleri onlara efsane gibi görünüp inanmadılar", gögerçin kimi onın üstüne nāzil oldı "güvercin gibi onun üzerine indi", eli o biri kimi sag̀ oldı "eli diğeri gibi iyileşti".

béle "birlikte, sonra" 
Eserde edat olarak "birlikte ve sonra" olmak üzere iki farklı anlamda kullanılmıştır.

hamısı inen béle "hepsiyle birlikte", yataq inen béle "yatak ile birlikte", bundan béle insan avçısı olacaqsan "bundan sonra insan avcısı olacaksın".

béle sözcüğü zarf olarak da kullanılmıştır. Söz konusu durumda béle "öyle, böyle, şöyle" gibi anlamlar vermektedir.

ne içün bize béle éyledin "niye bize böyle davrandın?", iki gemini béle doldurdılar ki batmağa başladılar "iki gemiyi öyle doldular ki batmaya başladılar", günlerin birisinde béle vāqi' oldı ki "günlerin birinde şöyle gerçekleşti".

sora "sonra"

İran Türk ağızlarının genelinde sọra sözcüğü $\mathrm{n}>\varnothing$ değişimi sonucunda sora "sonra" biçimine dönüşmüştür.

sekkiz gün sora "sekiz gün sonra", év șāhibi durub qapın bag̀llyandan sora "ev sahibi kalkıp kapıyı kapattıktan sonra", olar tamam olandan sora ac oldı "onlar bittikten sonra acıktı", tamam éyliyenden sora Kefernahum'a girdi "bitirdikten sonra Kefernahum'a girdi", üç günden sora vāqi' oldı "üç günden sonra gerçekleşti".

\section{ötri "ötürü"}

Günümüzde ölçünlü Azerbaycan Türkçesinde düzlük-yuvarlaklık uyumuna bağlanan ötri edatı eserde pek çok örnekte bulunmaktadır.

çoh żadlardan ötri "birçok şeyden ötürü", onı ahtarmaqdan ötri Urşelim'e qayıtdılar "onu aramak için Urşelim'e döndüler", du’a éylemekden ötri dag்a çıhdı "dua etmek için dağa çıktı", ondan ötri ki sen seht ādem sen "sert birisi olduğun için".

savay "başka"

Eserde birçok örnekte gördüğümüz savay "başka" edatı günümüzde İran Türk ağızlarında savay, sovay, suvay vb. biçimlerinde yaygın olarak görülür. Sözcük Arapça sevā' "başka, ayrı" sözcügüünün değişime uğramış şeklidir. Söz konusu sözcük ölçünlü Azerbaycan Türkçesinde savay veya savayı şeklinde kullanılmaktadır.

qızın ata ve anasından savay héç kimi girmege qoymadı "kızın ata ve anasından başka hiç kimsenin girmesine izin vermedi", bu bîgānelerden savay birisi tapılmadı "bu yabancılardan başka kimse bulunmadı", yalquz Allah'dan savay günahları bag̀ışlamağa kim qādirdir "yalnız Allah'tan başka günahları kim bağışlayabilir?", kāhinlerden savay héç kime cāyiz degil idi "kahinlerden başka kimseye caiz değil idi".

\section{Ek-Fiil}

Ad soylu sözcüklerin yüklem görevinde kullanılmasını sağlayan ve birleşik fiil çekimlerinde de görev alan $i$ - fiili günümüzde ölçünlü Azerbaycan Türkçesi ve İran Türk ağızlarında genelde ekleşmiş biçimde kullanılmaktadır. Ancak eserin geneline baktığımızda $i$ - fiili umumiyetle ayrı yazılmıştır.

şerîr ruhlardan ve mereżlerden șaǵalmış idiler "kötü ruhlardan ve hastalıklardan iyileşmişlerdi", vaqtîki daġdan yénür idiler "dağdan indikleri zaman", Żekeriyya adlı bir kāhin var idi ve onın 'avratı Hārun qızlarından olub adı Elișabet idi "Zekeriya adında bir kâhin vardı ve onun eşi Harun kızlarındandı, adı Elizabet idi", bir qāżi var idi ki ne Allah'dan qorhar idi ve 
ne halqdan utanurdı "ne Allah'tan korkan ne de halktan utanan bir kadı vardı", bir tut aġacina çıhdı çünki oradan géçecek $i d i$ "bir dut ağacına çıktı çünkü oradan geçecekti".

\section{Bildirme Eki}

Eserde, öğrenilen geçmiş zaman ve gelecek zaman ekleri genellikle bildirme ekiyle birlikte gelmektedir. Adlar üzerine de gelen $-d I r /-d U r$ eki günümüzde İran Türk ağızlarında genellikle -dI/-dU biçiminde (qız gözeldi "kız güzeldir", bu düzdü "bu doğrudur" vb.) kullanılmaktadır.

ama gözlerinden gizlenübdür "ama gözlerinden saklanmıştır", vaqt yahıılaşubdur amma oların dalınca gétmeyin "vakit yakınlaşmıştır ancak onların arkasından gitmeyin", su küzesi aparan bir nefer size rast gelecekdir "su testisi götüren bir kişi size rast gelecektir", atamın işlerinde olmaq mene vācibdir "atamın işlerini yapmak bana vaciptir", od inen t'emid vérecekdir "ateş ile vaftiz edecektir", günahları bağışlamag்a kim qādirdir "günahlarını kim affedebilir?", köhnesi daha yahşıdır "eskisi daha iyidir".

\section{-raq Eki}

Günümüzde gerek ölçünlü Azerbaycan Türkçesinde gerekse İran Türk ağızlarında seyrek olarak gördüğümüz -raq "en, daha" eki eserde yaygın biçimde kullanılmaktadır.

Allah'ın melekūtında küçükraq olan ondan böyükdür "Allah'ın melekûtında en küçük olan ondan daha büyüktür", āsānraq olacaqdır "daha kolay olacaktır", ondan quvvetliraq "ondan daha güçlü", devenin igne sūrahııdan géçmegi āsānraqdır "devenin iğne deliğinden geçmesi daha kolaydır".

\section{Soru Eki}

Ölçünlü Azerbaycan Türkçesinde soru ekinin kullanılmasına karşın günümüzde İran Türk ağızlarında soru eki kullanılmamaktadır. Bu ağızlarda soru son hecedeki vurgu ile belirlenir. Üzerinde çalıştığımız İncil tercümesinde de soru eki görülmemektedir. Cümleleri soru hâline getirmek için Farsça soru sözcüğü àya kullanılmıştır. Bu durum yazıda vurguyu gösterememekten kaynaklanmaktadır, çünkü günümüzde bile āyā sözcüğü İran Türk ağızlarında kullanılmaz. Eserde gördüğümüz bu tarz cümlelerin yapısı genellikle Farsça cümle yapısına uymaktadır.

$\bar{a} y \bar{a}$ istirsen İliya éyledigi kimi biz de emr éyliek ki gögden od düşüb olarn telef éylesün? "İliya'nın yaptığı gibi bizim de onları mahvetmek için gökten taşın düşmesini emretmemizi istiyor musun?", āyā görmürsen ki bacım meni hidmet éylemekde yalquz qoyubdur? "k1z kardeşimin beni hizmet etmekte yalnız bıraktığını görmüyor musun?", āya éşigi qayıran içerini de qayırmıyubdur? "dışı düzenleyen içi de düzenlememiş mi?, āy $\bar{a}$ bu meŝeli bize déyirsen ya hamılara? "acaba bu meseli sadece bize mi diyorsun yoksa herkese mi?", $\bar{a} y \bar{a}$ Allah öz séçilmişlerinin dādına ki géce ve gündüz on çag̀ırtrlar yétişmiyecekdir? "Allah, gece gündüz onu çağıran kendi seçilmişlerinin yardımına gelmeyecek mi?", bize dé ki āyā Mesih sensen? "bize söyle acaba Mesih sen misin?".

\section{Cümle Yapısı}

İran Türk ağızları uzun zaman Farsça ile aynı coğrafyada kullanıldığı için farklı açılardan söz konusu dilin etkisi altında kalmıştı. Bu etkilerin en belirgin izlerini cümle yapılarında görebiliriz. Özellikle son zamanlarda İran Türk ağızları söz dizimsel bakımdan ciddi değişime uğramıştır. Üzerinde çalıştığımız eserde de akıcı bir Türkçenin kullanılmasına rağmen yer yer cümle yapılarında Farsçanın etkisi görülmektedir. 
hansı ana var ki oğlı ondan çörek istese ona daş vére "oğluna ekmek istediği halde taş veren ana var mı?", ve vaqtîki o danışur idi bir Ferisi ondan hāhiş éyledi "o konuştuğunda bir Ferisi ondan rica etti", çünki Hirodes istir seni öldürsün "çünkü Hirodes seni öldürmek istiyor", biz istemirik bu şehș bizim üstümüze pādişahlıq éylesün "biz bu kişinin bize padişahlık etmesini istemiyoruz", 'İsā'nın yanına yahıılaşdı ki onı öpsün "İsa'yı öpmek için ona yakınlaştı", bilmirdi ne danışırdı "ne konuştuğunu bilmiyordu".

Farsça cümle yapısının etkisine dair örnek bir şema:

\begin{tabular}{|c|c|c|c|c|c|c|c|c|c|c|}
\hline hanst & ana & var & $k i$ & og $l l$ & ondan & çörek & istese & ona & daş & vére \\
\hline II & I] & II & I & 11 & $\sqrt{7}$ & I & I] & $\sqrt{1}$ & II & II \\
\hline & māder & est & ké & pésereş & $e z \bar{u}$ & $n \bar{a} n$ & béhāhed & bé $\bar{u}$ & eng & ned \\
\hline
\end{tabular}

\section{SONUÇ}

Oğuz Türkçesinin çeşitli lehçe ve ağızlarını ve bunların gelişim sürecini dikkate aldığımızda zengin bir dil malzemesiyle karşı karşıya geliyoruz. Son yüzyıllarda belirli çizgilerle birbirinden ayrılmış olan söz konusu lehçe ve ağızlar dil çalışmaları için oldukça önemlidir. Bu bağlamda üzerinde durduğumuz Lukanın İncili Azerbaycan ve İran sahasıyla ilgili yapılacak olan dil çalışmaları için aydınlatıcı bir kaynak niteliğindedir. Eserde görülen başta ağız özellikleri ve diğer dil malzemeleri, Azerbaycan ve İran'da Türkçenin gelişim sürecini takip etmemizde yardımcı olabilir. Söz konusu eser içerdiği dil malzemesinin yanı sıra tür bakımından da önemlidir. Bu eser, İslami içerikli olmayıp da Hristiyanlığa ait olması itibariyle ayrıca önem arz etmektedir. Eserin basıldığı yer ve tarih belli olmasa da dil malzemesi sayesinde Lukanın İncili'nin XIX. yüzyılda ve büyük bir ihtimalle İran sahasında basıldığı tahmin edilmektedir. Eserde, Oğuz Türkçesinin dil özellikleri bulunmakla birlikte belli bir ağzın özellikleri de açık bir şekilde görülmektedir. Söz konusu özelliklerin birçoğunu günümüzde İran Türk ağızlarında da görebiliriz. Bu özellikleri kısaca şu şekilde sıralayabiliriz: / $\mathrm{y} /$ sesinin kullanılmaması, $\mathrm{y}>\mathrm{v}, \mathrm{y}>\mathrm{y} \mathrm{y}>\mathrm{q} / \mathrm{nq}$ gibi ses değişmelerinin yaşanması, inen "ile" edatı ve onun ekleşmiş durumu olan -nAn ekinin kullanılması, sora "sonra", kimin "kadar", béle "birlikte, sonra", savay "başka" gibi edatların kullanılması, olar "onlar" ve bular "bunlar" gibi biçimlerin kullanımı, soru ekinin kullanılmaması, Farsça cümle yapısının sık sık görülmesi vb. Bu hususları dikkate aldığımızda eserin İran sahasında kaleme alındığı söylenebilir.

\section{SUMMARY}

Translating the religious texts has a special place in the history of the Turkish language, and its pioneers were the Uyghurs. Due to the spread of Islam among the Turks, the main sources of this religion, including the Quran, jurisprudential and historical books, were translated into Turkish. All of these works, regardless of the political and religious purposes of these translations, are valuable resources for the Turkish language, and it can be said that these works have played a significant role in the transformation of the Turkish language. Translating the religious texts among the Turks is not limited to Islamic sources, and other religious texts have also been translated into Turkish. One of these sources is the Christian scripture, the Bible. According to the available evidence, the Bible was first translated into Turkish in the Old Uyghur period and has been translated many times in different regions during the Ottoman era. One of the translations of the Bible is called the Gospel of Luke, which we have addressed in this paper. This scripture, which is kept in the 
National Library of Iran, has been translated into one of the Azerbaijani Turkic dialects, and this is the most important feature of this book. There is no exact information on its translator and the time of translation, however, taking into account the linguistic features and the type of translation, the present work is thought to date back to the nineteenth century. This paper has analyzed the linguistic features of the mentioned book, and if necessary, compared it with the standard Azerbaijani Turkic and the Iranian Turkic dialects. The most important linguistic features of this work can be summarized as follows:

This work has followed a coherent spelling system, and the diacritical mark has been used to read some words correctly. In Gospel of Luke, in comparison with standard Azerbaijani Turkic, the rule of labial harmony is not fully implemented (gizledüb, düşdi, olmasunlar, üçinci). The conversion of $y>v$ and $y>y(\varnothing)$ is one of the most important phonetic features of this work (ogilv1, atava, atayız, adız). Existing the consonant $/ y /$ at the beginning of some words (yüzük, yüz, yulduz, yürek). Using two types of suffixes to indicate past perfect (almışam, tutmamışıq, gelüb, qoyublar). Necessitative mood are usually made up of two words, lāzım and gerek (qalmaġım lāzımdır, gerek tekmil olunsun). Using postposition such as: inen, kimin, dekin, kimi, béle, sora, ötri, savay. Not using the $\mathrm{mI}$ question suffix in question sentences, and using the question word of āyā instead. The effect of Persian sentence structure on some sentences is the most important linguistic features of this book.

The examining works such as the Gospel of Luke, make possible exploring the evolution of Azerbaijani Turkic in the last two centuries. Moreover, according to the type and content of this work, the position of the Turkish language in Iran, in recent centuries, can be evaluated.

Makale Bilgileri

$\begin{array}{ll}\text { Etik Kurul Kararı: } & \text { Etik Kurul Kararından muaftır. } \\ \text { Katılımcı Rızası: } & \text { Katılımcı yoktur } \\ \text { Mali Destek: } & \begin{array}{l}\text { Çalışma için herhangi bir kurum ve projeden mali destek } \\ \text { alınmamıştır. }\end{array} \\ \text { Çıkar Çatışması: } & \begin{array}{l}\text { Çalışmada kişiler ve kurumlar arası çıkar çatışması } \\ \text { bulunmamaktadır. } \\ \text { Çalışmada kullanılan görsellerle ilgili telif hakkı } \\ \text { sahiplerinden gerekli izinler alınmıştır. }\end{array} \\ \text { Article Information } & \begin{array}{l}\text { Exempt from the Ethics Committee Decision. } \\ \text { No participant }\end{array} \\ \text { Informed Consent: } & \text { No financial support from any institution or project. } \\ \text { Financial Support: } & \text { No conflict of interest. } \\ \text { Conflict of Interest: } & \text { The required permissions have been obtained from the } \\ \text { Copyrights: } & \text { copyright holders for the images and photos used in the } \\ & \text { study. }\end{array}$




\section{KAYNAKÇA}

Argunşah, M. (2013). Çağatay Türkçesi. İstanbul: Kesit Yayınları.

Azərbaycan Elmlər Akademiyası Nəşriyyatı (2006). Azərbaycan dilinin izahli lüğəti. Bakı: Yazar.

Bicbabaei, B. (2012). Malekan (Melek Kendi) ili ağzı (Yayımlanmamış doktora tezi). Ankara Üniversitesi, Ankara.

Doğan, T. (2010). Urmiye ağızları. (Yayımlanmamış doktora tezi). Kırıkkale Üniversitesi, Kırıkkale.

Ercilasun, A. B. (2008). Türk dili tarihi. Ankara: Akçağ Yayınları.

Ercilasun, A. B. (Ed.). (2007). Türk lehçeleri grameri. Ankara: Akçă̆ Yayınları.

Ercilasun, A. B. ve Akkoyunlu, Z. (2018). Dîvânu lûgati't-Türk. Ankara: Türk Dil Kurumu Yayınları.

Ergin, M. (1971). Azeri Türkçesi, İstanbul: İstanbul Üniversitesi Edebiyat Fakültesi Yay.

Ergin, M. (2009). Türk dil bilgisi. İstanbul: Bayrak Yayınları.

Gökdağ, B. A. (2006). Salmas ağzı Güney Azerbaycan Türkçesi üzerine bir inceleme. Çorum: KaraM Yayınları.

Gülensoy, T. (2007). Türkiye Türkçesindeki Türkçe sözcüklerin köken bilgisi sözlüğü. Ankara: Türk Dil Kurumu Yayınları.

Günşen, A. (2006). göster- ve görset- / körset- fiillerinin yapısı üzerine. Sosyal Bilimler Enstitüsü Dergisi, 20, 35-49.

Harman, Ö. F. (2002). Kitâb-1 mukaddes. İslam Ansiklopedisi (C. 26, s. 75-76). Ankara: Türkiye Diyanet Vakfı Yayınları.

https://dergipark.org.tr/tr/pub/erusosbilder/issue/23753/253076

https://historyofturkishbible.files.wordpress.com/2015/07/tc3bcrkc3a7e-km-tarihi_versions.pdf

Karini, J. (2009). Erdebil ili ağızları. (Yayımlanmamış doktora tezi). Gazi Üniversitesi, Ankara.

Korkmaz, Z. (2010). Gramer terimleri sözlüğü. Ankara: Türk Dil Kurumu Yayınları.

Privratsky, B. G. (2015). Kitabı mukaddes'in Türkçe tercümelerinin tarihçesi, $16-21$ yy (C. Şakırgil, Çev.). Erişim adresi:

Rezaei, M. (2016). İran - Zencan bölgesi, Kaydar ve yöresi ağızları. Tahran: Âvâyé Kkâver Yayınları.

Rezaei, M. (2018). Türkiye Türkçesi ile Azerbaycan Türkçesi arasında bulunan fonetik farklılıklar. Uluslararası Türk Lehçe Araştırmaları Dergisi (Türklad). 2, 59-75. https://doi.org/10.30563/turklad.455124

Timurtaş, F. (2005). Eski Türkiye Türkçesi. Ankara: Akçağ Yayınları.

Türk Dil Kurumu (2005). Türkçe sözlük. Ankara: Yazar.

SEFAD, 2020; (44): 103-118 
EK 1. Örnek Sayfalar

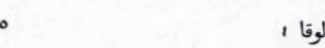

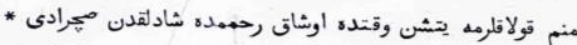

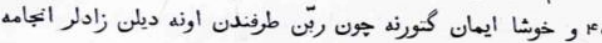

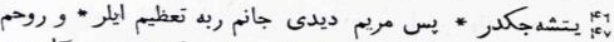

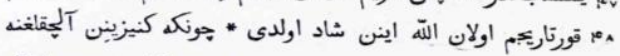

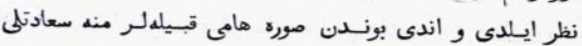

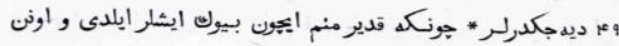

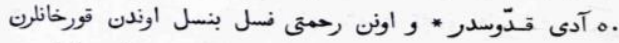

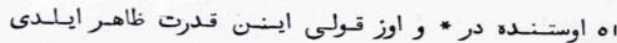

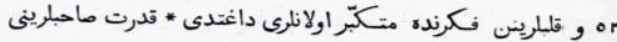
or

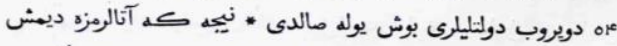

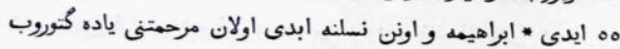

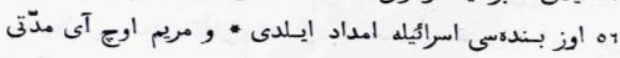

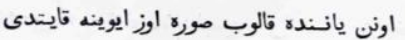

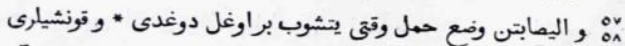

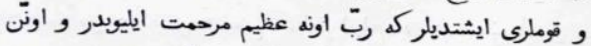

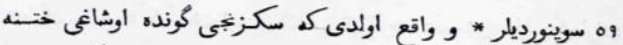

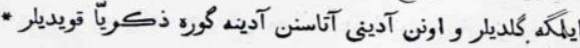

$$
\text { لوقا }
$$

\section{Ir}

رئيسى عيسىنن سبت كرينده شفا ويرمكندن آجقلانوب خلقه

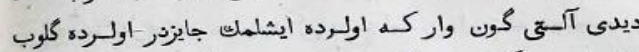

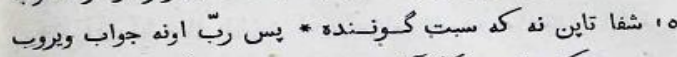

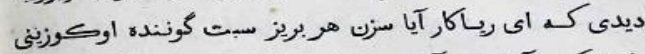

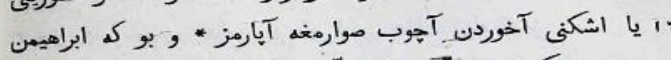

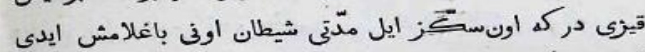

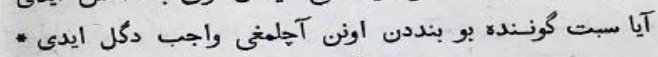

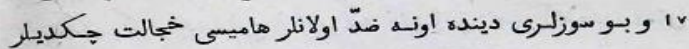

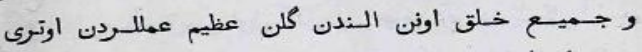
سوينورايديلر

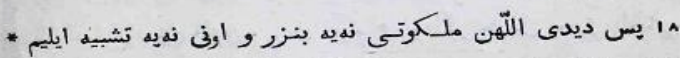

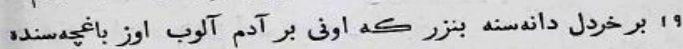

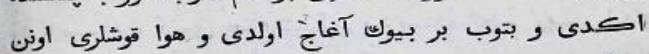
بوداقلرينه قونديلر

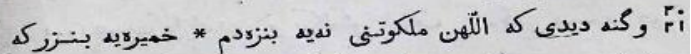

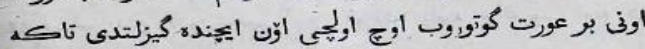

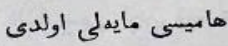
r و شهرلرى وكندلرى كزوب تعليم ويرماينَن اورشليم طرفنده 